\title{
Mitigating cadmium accumulation in greenhouse lettuce production using biochar
}

\author{
Ruilun Zheng ${ }^{1}$ - Guoxin $\mathrm{Sun}^{2} \cdot \mathrm{Cui} \mathrm{Li}^{1} \cdot$ Brian J. Reid ${ }^{3} \cdot{\text { Zubin } \mathrm{Xie}^{4} \cdot \text { Bo Zhang }}^{5}$. \\ Qinghai Wang ${ }^{1}$
}

Received: 4 May 2016 / Accepted: 18 December 2016/Published online: 10 January 2017

(C) Springer-Verlag Berlin Heidelberg 2017

\begin{abstract}
Greenhouse experiments were conducted to investigate the influence of rice straw biochar (RSB) on soil cadmium (Cd) availability and accumulation in lettuce. The RSB was applied either in bands or broadcast in the test site of four greenhouses with soil $\mathrm{Cd}$ concentrations ranging from 1.70 $3.14 \mathrm{\mu g} \mathrm{g}^{-1}$. Biochar doses applied in bands were half of those broadcast. The Cd levels in the shoots of lettuce were observed to be reduced by up to $57 \%$ with increasing RSB application rate $\left(0,6,12,18 \mathrm{tha}^{-1}\right)$. Following RSB application, shoot $\mathrm{Cd}$ concentrations of lettuce were reduced to below the Chinese threshold value set for food, and hazard quotients for $\mathrm{Cd}$ associated with vegetable consumption were reduced from $0.70-1.11$ to $0.42-0.65$. A decrease in soil bulk density (11\%) and increases in water holding capacity (16\%), available
\end{abstract}

Responsible editor: Elena Maestri

Electronic supplementary material The online version of this article (doi:10.1007/s11356-016-8282-9) contains supplementary material, which is available to authorized users.

Qinghai Wang

qinghaiw@sina.com

1 Research and Development Center for Grasses and Environment, Beijing Academy of Agriculture and Forestry Sciences, Beijing 100097, People's Republic of China

2 State Key Lab of Urban and Regional Ecology, Research Center for Eco-Environmental Sciences, Chinese Academy of Sciences, Beijing 100085, People's Republic of China

3 School of Environmental Sciences, University of East Anglia, Norwich Research Park, Norwich NR4 7TJ, UK

4 State Key Laboratory of Soil and Sustainable Agriculture, Jiangsu Biochar Engineering Center, Institute of Soil Science, Chinese Academy of Sciences, Nanjing 210008, People's Republic of China

5 Institute of Biological and Environmental Sciences, University of Aberdeen, Aberdeen AB24 3UU, UK phosphorus (30\%), available potassium (197\%), and lettuce yield (15\%) were observed after RSB application. Multiple linear regression analysis suggested that the soil extractable $\mathrm{Cd}$ level (but not biomass dilution) and soil bulk density, as influenced by RSB addition, were the dominant contributors to the shoot $\mathrm{Cd}$ levels in lettuce and lettuce yield, respectively. These results highlight the potential for RSB to mitigate the phytoaccumulation of $\mathrm{Cd}$ and thereby to reduce human exposure from vegetable consumption. Application of biochar in band, rather than broadcasting over the entire area, represents an opportunity to halve the biochar cost while retaining a good remediation effect.

Keywords Biochar · Cadmium · Leaf lettuce $\cdot$ Greenhouse · Hazard quotient

\section{Introduction}

Cadmium $(\mathrm{Cd})$ is a nonessential and toxic metal element. Exposure to $\mathrm{Cd}$ has been associated with many diseases in humans, such as nephrotoxicity, osteoporosis, neurotoxicity, and adverse endocrine and reproductive effects (EFSA 2009). Among the toxic metals and metalloids, $\mathrm{Cd}$ is notable for its ease of uptake by crops and thus its ability to enter the food chain. Many studies have shown the contamination of farmland soils by $\mathrm{Cd}$ in China, and consequently, $\mathrm{Cd}$ contamination of food crops and vegetables have been frequently reported (Wang et al. 2005; Li et al. 2006; Khan et al. 2008; Zeng et al. 2008; Zheng et al. 2015a). In peri-urban areas of China, the main agricultural activities are livestock production and vegetable cultivation. Organic fertilizers from livestock slurry and wastewater sludge are easily available and widely used in peri-urban arable lands. Thus, soils can be contaminated with $\mathrm{Cd}$ through the application of livestock manures, fertilizers and agrochemicals, 
sewage irrigation, and atmospheric deposition (Luo et al. 2009). Urban and peri-urban agriculture such as vegetable greenhouses are more vulnerable to metal contamination because of the frequent and heavy input of fertilizers and irrigation. Indeed, vegetables produced in peri-urban greenhouses have been reported to be contaminated with $\mathrm{Cd}$ because of the excessive use of $\mathrm{Cd}$ containing manures (Ju et al. 2007; Luo et al. 2009; Yang et al. 2009; Yang et al. 2013).

Biochar is receiving increasing attention because of its potential benefits in agricultural and environmental contexts such as mitigation of global warming (Sui et al. 2016), improvement of soil quality (Olmo et al. 2016), and the increase of soil nutrient availability and water retention capacity (Liu et al. 2016; Sorrenti and Toselli 2016), and improvement of crop yield (Khan et al. 2013; Olmo et al. 2016). In recent years, there has been growing evidence that the application of biochar in soil could immobilize $\mathrm{Cd}$ and thereby reduce its accumulation within plants (Park et al. 2011; Zheng et al. 2012; Khan et al. 2014; Zheng et al. 2015a). Incorporation of biochars into soil has been shown to result in considerable immobilization of $\mathrm{Cd}$ in soils and reduced $\mathrm{Cd}$ accumulation in Indian mustard, wheat and rice (Park et al. 2011; Zheng et al. 2013, 2015a). It follows that biochar could decrease the transfer of $\mathrm{Cd}$ from soils to other vegetables and reduce $\mathrm{Cd}$ exposure associated with vegetable consumption.

Many studies have reported the effect of broadcast biochar on the immobilization of $\mathrm{Cd}$ in soils. However, biochar cost remains too high for such an approach to be popularized at a large scale. The biochar cost can be halved by using band application instead of broadcast application; however, the effectiveness of band placement versus broadcast application on Cd immobilization remains unclear. In addition, there remains insufficient information regarding the effect of biochar amendment on $\mathrm{Cd}$ accumulation in greenhouse vegetables that are subject to excessive irrigation and inputs of fertilizers and manures. In the present study, both broadcast and band applications of biochar were employed for the purpose of $\mathrm{Cd}$ sequestration in a suburban greenhouse soil. Specifically, the research investigated the following: (i) the influence of biochar additions on $\mathrm{Cd}$ immobilization and accumulation in leaf lettuce grown in greenhouses; (ii) the effectiveness of broadcast and band biochar application for the mitigation of $\mathrm{Cd}$ accumulation in vegetables; and (iii) the reduction in $\mathrm{Cd}$ intake by humans and hazard quotient (HQ) associated with vegetable consumption.

\section{Materials and methods}

\section{Study area and biochar description}

The experiment was carried out in greenhouses in a vegetable garden in Hebei province, less than $2 \mathrm{~km}$ from Beijing, China, and was initiated in 2015. Vegetables produced in this garden are primarily supplied to suburban residents of Beijing. The vegetable garden soil was historically contaminated with $\mathrm{Cd}$ due to excessive inputs of livestock manure in the 1990s.

Biochar was produced from rice straw in a pyrolysis system with a rotatory kiln (12 m long and $0.9 \mathrm{~m}$ diameter) by Nanjing Qinfeng Crop Straw Technology Company, Jiangsu Province, China. Rice straw was placed into the rotatory kiln and charred in the absence of air for $1 \mathrm{~h}$ after the kiln temperature was raised to $500{ }^{\circ} \mathrm{C}$ by heating up for about $3 \mathrm{~h}$. The obtained biochar was ground and passed through 2-mm mesh sieves. Selected physicochemical properties of the biochar are presented in Table 1.

\section{Experimental design}

Soil Cd concentrations in soil samples from 21 greenhouses of the vegetable garden were tested before experiments commenced (Table 2). Soil Cd concentrations were determined from three soil samples per greenhouse. Each sample was bulked from three subsamples that were randomly taken from each of the greenhouses using the "S" sampling method (soil was collected from a depth between 0 and $20 \mathrm{~cm}$; about $200 \mathrm{~g}$ per subsample). Greenhouse 18 (G18) was identified as having a soil Cd concentration $\left(2.28 \mu \mathrm{g} \mathrm{g}^{-1}\right)$ in the middle of the range of concentrations observed ( 1.34 to $3.14 \mu \mathrm{g} \mathrm{g}^{-1}$ ). G18 was therefore selected for a preliminary study (Experiment 1 ). Thereafter, Greenhouses 5, 6, 20, and 21 (G5, G6, G20, and G21) were selected for a further study (Experiment 2). G5 and G6 provided soils with relatively lower $\mathrm{Cd}$ concentrations (1.70-1.76 $\mathrm{g} \mathrm{g} \mathrm{g}^{-1}$ ), while G20 and G21 had higher Cd concentrations $\left(2.62-3.14 \mu \mathrm{g} \mathrm{g}^{-1}\right)$.

Experiment 1 Rice straw biochar (RSB) was applied in G18 using the broadcasting method at different rates $(0,6,12$, $\left.18 \mathrm{tha}^{-1}\right)$. Four plots $(6.5 \mathrm{~m} \times 3.8 \mathrm{~m})$ were used for each RSB addition rate. Biochar $(<2 \mathrm{~mm})$ was added to the soil and mixed thoroughly with the topsoil (0-20 cm depth) using rotary cultivator plowing. In keeping with common practice of local farmers, cattle manure and chemical fertilizers were applied as basal fertilizers at $20 \mathrm{t}$ manure $\mathrm{ha}^{-1}, 0.1 \mathrm{t}_{2} \mathrm{O}_{5} \mathrm{ha}^{-1}$, and $0.2 \mathrm{t}$ nitrogen $(\mathrm{N}) \mathrm{ha}^{-1}$ (no potassium $(\mathrm{K})$ was added). The $\mathrm{Cd}$ concentrations of the applied manure and phosphorus $(\mathrm{P})$

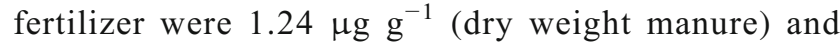
$0.95 \mu \mathrm{g} \mathrm{g}^{-1} \mathrm{P}_{2} \mathrm{O}_{5}$, respectively. Following RSB and fertilizer application, leaf lettuce (Lactuca sativa L. var. ramosa Hort.) seedlings, which had been raised for 4 weeks, were transplanted into experimental plots. Water management was performed following conventional practices by the local farmers.

Experiment 2 RSB was applied in G5, G6, G20, and G21 to allow lower (1.70-1.76 $\left.\mathrm{g} \mathrm{g} \mathrm{g}^{-1}\right)$ and higher levels (2.62- 
Table 1 Physicochemical properties and elemental concentrations in biochar

\begin{tabular}{|c|c|c|c|c|c|c|c|c|c|c|c|c|}
\hline \multirow[t]{2}{*}{$\mathrm{pH}$} & \multirow[t]{2}{*}{$\mathrm{TC}(\%)$} & \multirow[t]{2}{*}{$\mathrm{TN}(\%)$} & \multicolumn{4}{|c|}{ Total heavy metals $\left(\mu \mathrm{g} \mathrm{g}^{-1}\right)$} & \multicolumn{4}{|c|}{ Water-soluble heavy metals $\left(\mu \mathrm{g} \mathrm{g}^{-1}\right)$} & \multicolumn{2}{|c|}{ Water-soluble nutrients $\left(\mathrm{mg} \mathrm{g}^{-1}\right)$} \\
\hline & & & $\mathrm{Cd}$ & $\mathrm{Zn}$ & $\mathrm{Pb}$ & As & $\mathrm{Cd}$ & $\mathrm{Zn}$ & $\mathrm{Pb}$ & As & $\mathrm{P}$ & $\mathrm{K}$ \\
\hline 10.7 & 45.1 & 1.59 & 0.145 & 266.3 & 14.4 & 0.77 & 0.004 & 0.34 & 0.081 & 0.25 & 0.66 & 47.6 \\
\hline
\end{tabular}

$3.14 \mu \mathrm{g} \mathrm{g}^{-1}$ ) of Cd (Table 1) to be considered for both broadcast and band RSB applications.

Broadcast application of RSB was at a rate of $10 \mathrm{tha}^{-1}$ in the lower $\mathrm{Cd}$ treatments (G5) and at an increased rate of $16 \mathrm{t} \mathrm{ha}^{-1}$ in the higher $\mathrm{Cd}$ treatments (G21). The decision to use two different rates of application was informed by Experiment 1 (see "Results" section) wherein an application of $10 \mathrm{tha}^{-1}$ was deemed to be a probable minimum application to reduce leaf $\mathrm{Cd}$ concentrations to below regulatory limits (see "Results;" Fig. 1) in the lower Cd concentration soil (G5). Given that soil Cd concentration in G5 was approximately two thirds (Table 1) of that in the high concentration soil (G21), the biochar application was scaled accordingly $\left(16 \mathrm{tha}^{-1}\right)$ in the treatment of the soil with the higher $\mathrm{Cd}$ concentration.

To contrast with the broadcast application of RSB, G6 (lower Cd) and G20 (higher Cd) were amended with RSB using band application. Band application focused the RSB onto only half of the plot area (the zone around the growing lettuce plants). Thus, applications of only 5 and $8 \mathrm{tha}^{-1}$ were made in G6 and G20, respectively.

Table 2 Cd concentrations in soils $\left(\mu \mathrm{g} \mathrm{g}^{-1}\right)$ in 21 greenhouses. Values are given as mean \pm standard deviation $(n=3)$

\begin{tabular}{|c|c|c|c|}
\hline Greenhouses & Total soil Cd & Greenhouses & Total soil Cd \\
\hline G1 & $1.34 \pm 0.14 \mathrm{~h}^{\mathrm{a}}$ & G12 & $2.01 \pm 0.20 \mathrm{cdef}$ \\
\hline G2 & $1.34 \pm 0.14 \mathrm{~h}$ & G13 & $2.04 \pm 0.22 \mathrm{cdef}$ \\
\hline G3 & $1.40 \pm 0.21 \mathrm{~h}$ & G14 & $2.10 \pm 0.34 \mathrm{cdef}$ \\
\hline G4 & $1.49 \pm 0.26 \mathrm{gh}$ & G15 & $2.11 \pm 0.31 \mathrm{cdef}$ \\
\hline$G 5^{\mathrm{d}}$ & $1.70 \pm 0.32 \mathrm{fgh}$ & G16 & $2.16 \pm 0.29 \mathrm{cde}$ \\
\hline G6 & $1.76 \pm 0.15 \mathrm{efgh}$ & G17 & $2.19 \pm 0.26$ bcde \\
\hline G7 & $1.78 \pm 0.28 \mathrm{efgh}$ & G18 & $2.28 \pm 0.30 \mathrm{bcd}$ \\
\hline G8 & $1.88 \pm 0.24 \mathrm{defg}$ & G19 & $2.32 \pm 0.37 b c$ \\
\hline G9 & $1.96 \pm 0.17 \mathrm{cdef}$ & $G 20$ & $2.62 \pm 0.24 \mathrm{ab}$ \\
\hline G10 & $1.98 \pm 0.27 \mathrm{cdef}$ & $G 21$ & $3.14 \pm 0.36 \mathrm{a}$ \\
\hline G11 & $2.00 \pm 0.23 \mathrm{cdef}$ & & \\
\hline Background soil & $0.094^{\mathrm{b}}$ & Regulatory limit & $0.6^{\mathrm{c}}$ \\
\hline
\end{tabular}

Different letters indicate significant difference at $p<0.05$ between greenhouses $(n=3)$

${ }^{a}$ Concentration in background soil of Hebei, China (CNEMC 1990)

${ }^{\mathrm{b}}$ Environmental quality standard for agricultural soils of China, GB15618-1995

${ }^{\mathrm{c}}$ Greenhouses indicated in italic font were selected for the present study
In all instances, four plots $(6.5 \mathrm{~m} \times 7.5 \mathrm{~m})$ were produced for each treatment type in every greenhouse (four control plots, without RSB addition, were also established in each green house). Regarding treatment in band RSB application, lettuce was planted within the biochar addition band, and soil and plant samples were also taken in these bands. The water and fertilizer management were same as in Experiment 1.

\section{Sampling and chemical analysis}

Topsoil samples were taken at five random points, away from the edge of the experimental plots, 2 weeks after RSB application. These five samples were combined to give a composite sample for the plot. Soil samples were air-dried, crushed, and sieved with 2-mm mesh prior to analysis (see below). Two soil samples were taken using cutting rings from the surface layer $(0-10 \mathrm{~cm})$ of each plot for analysis of soil bulk density (SBD) and water holding capacity (WHC).

Plant samples were taken after 2 months of growth. At harvest, shoots of lettuce were cut above the soil surface, and their fresh weight was recorded immediately. Samples were then washed with tap water to remove any attached particles, thoroughly rinsed with deionized water three times, then homogenized in an electric blender and kept in clean polyethylene bags and refrigerated at $2{ }^{\circ} \mathrm{C}$ until analysis. The corresponding root samples $(0-20 \mathrm{~cm}$ depth) with attached soil were taken and washed with deionized water to dislodge adherent soil particles then dried at $70{ }^{\circ} \mathrm{C}$ for $48 \mathrm{~h}$. Aliquots $(2.0 \mathrm{~g})$ of the fresh shoot samples were weighed into $50 \mathrm{~mL}$ clean triangular flasks. Mixed acid of concentrated $\mathrm{HNO}_{3}$ and $\mathrm{HClO}_{4}(4: 1 v / v)(10 \mathrm{~mL})$ was added and allowed to stand overnight. The following day, after placing a small funnel on the mouth of the flasks, samples were digested on an electric hot plate $\left(4 \mathrm{~h}\right.$ at $\left.180^{\circ} \mathrm{C}\right)$. The digested solution was cooled and diluted to $25 \mathrm{~mL}$ with Millipore ultrapure water then filtered prior to elemental analysis (Yang et al. 2009). After grinding to a fine powder, aliquots $(0.15 \mathrm{~g})$ of the dry root samples were weighed and digested in the same way as shoot samples.

Finely ground $(<0.149 \mathrm{~mm})$ soil $(0.5 \mathrm{~g})$ and biochar samples $(0.2 \mathrm{~g})$ were digested in a glass tube using $\mathrm{HCl}, \mathrm{HNO}_{3}$, and $\mathrm{HClO}_{4}(3: 1: 1 \mathrm{v} / \mathrm{v})(10 \mathrm{~mL})$ for determination of total element concentrations ( $\mathrm{Lu}$ 2000; Zheng et al. 2015a). Available concentrations of $\mathrm{Cd}$, zinc $(\mathrm{Zn})$, iron $(\mathrm{Fe})$, manganese $(\mathrm{Mn})$ in the soil were assessed using diethylenetriaminepentaacetic 
Fig. 1 DTPA-extractable Cd concentrations, under biochar additions at different rates $(0,6$, $12,18 \mathrm{t} \mathrm{ha}^{-1}$ ) in greenhouse $\mathrm{G} 18$, in soils (a) and shoot $\mathrm{Cd}$ concentrations of leaf lettuce (Lactuca sativa L. var. ramosa Hort.) (b). Different letters above the bars indicate significant differences between treatments at $p<0.05(n=4)$ (a)

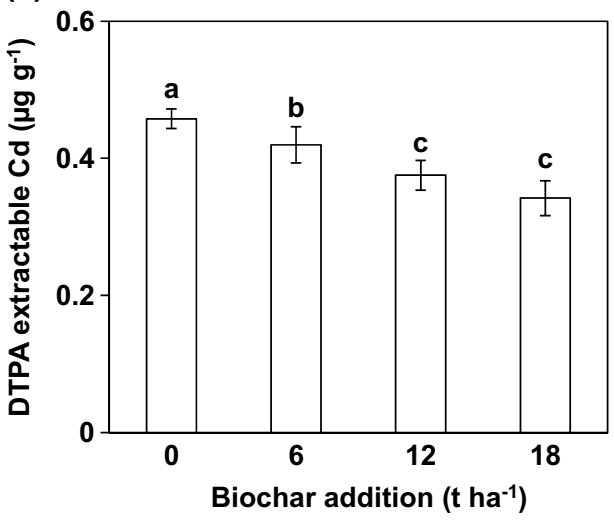

(b)

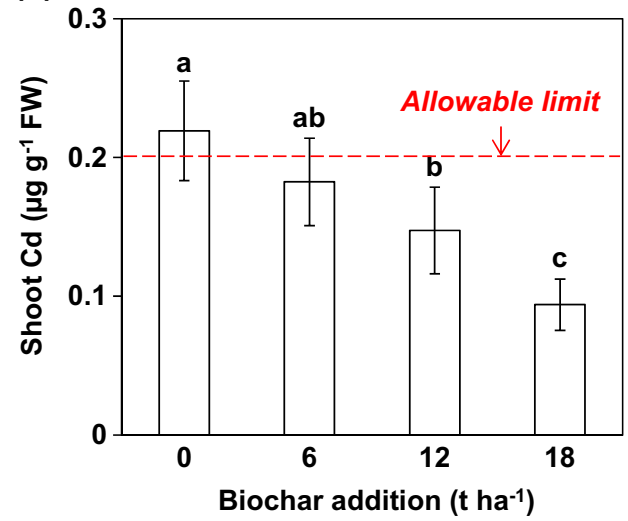

acid (DTPA) solution as the extractant (1:5 w/v) (Lu 2000; Ettler et al. 2007). The DTPA solution contained $0.005 \mathrm{M}$ DTPA, $0.01 \mathrm{M} \mathrm{CaCl}_{2}$, and $0.1 \mathrm{M}$ triethanol amine at $\mathrm{pH}$ 7.3. The DTPA $(50 \mathrm{~mL})$ was added to soil samples $(10 \mathrm{~g})$ contained within $100 \mathrm{~mL}$ flasks and shaken for $2 \mathrm{~h}$. Water extracts of biochar were carried out using 1:10 suspensions, shaken for $3 \mathrm{~h}$ and the supernatants filtered through a $0.45-\mu \mathrm{m}$ pore-size Millipore filter. Measurements of elemental concentrations were carried out using inductively coupled plasma mass spectroscopy (ICP-MS, 7500a, Agilent Technologies, USA) with indium isotopes $\left(\operatorname{In}^{115}\right)$ as internal standards $\left(10 \mu \mathrm{g} \mathrm{L}^{-1}\right)$ for $\mathrm{Cd}$ and ICP optical emission spectroscopy (ICP-OES, Optima 2000, PerkinElmer Co., USA) for P, K, calcium (Ca), magnesium (Mg), Fe, Mn, and $\mathrm{Zn}$. Certified reference material GBW07603 (bush twigs and leaves), spikes, and blanks were used for quality assurance. The recovery of these reference materials and spikes ranged from $85 \%$ to $112 \%$.

Total carbon (TC) and nitrogen (TN) analyses of biochar were conducted on a solid TC/TN analyzer (Vario EL III, Elementar Analysen systeme GmbH, Germany). Soil available concentrations of $\mathrm{N}, \mathrm{P}$, and $\mathrm{K}$ were determined using the alkaline hydrolysis diffusion method, sodium bicarbonate leaching-molybdenum antimony colorimetric method, and ammonium acetate extraction-flame photometric method, respectively (Lu 2000).

\section{Daily intake of $\mathrm{Cd}$ and $\mathrm{HQ}$}

The human estimated daily intake (EDI) of Cd through consumption of vegetables was calculated using the following equation (Eq. 1):

$\mathrm{EDI}=\frac{\mathrm{IRv} \times[\mathrm{Cd}] \mathrm{v}}{\mathrm{BW}}$

where $\mathrm{IR}_{v},[\mathrm{Cd}]_{v}$, and BW represent the vegetable intake rate per capita for rural resident in Beijing $\left(\mathrm{kg} \mathrm{day}^{-1} ; 279 \mathrm{~g}\right.$ day $^{-1}$ ) (BSY 2015), Cd concentrations in vegetable and average body weight $(62 \mathrm{~kg}$ ) (calculated according to CSY 2015 and NCDSR 2015), respectively.

The HQ indices for $\mathrm{Cd}$ in vegetable were calculated using the equation described by the US Environmental Protection Agency (USEPA 2014) (Eq. 2):

$\mathrm{HQ}=\frac{\mathrm{EDI}}{\mathrm{RfD}}$

where RfD represents the oral reference dose (1 $\mathrm{\mu g} \mathrm{kg}^{-1} \mathrm{day}^{-1}$ for Cd) (USEPA 2014).

\section{Statistical analysis}

All data were subjected to one-way analysis of variance. Significant differences were identified using the least significant difference test $(p<0.05)$. Multiple linear regressions using a stepwise method were obtained. Statistical analysis was performed using the SPSS 16.0 software (SPSS Inc., USA).

\section{Results}

\section{Characteristics of the soils and biochar}

Soil Cd concentrations were elevated in all greenhouses (1.34-3.14 $\left.\mu \mathrm{g} \mathrm{g}^{-1}\right)$ relative to background soil $\left(0.094 \mu \mathrm{g} \mathrm{g}^{-1}\right)$ (CNEMC 1990) by factors ranging from 14.3 to 33.4. These $\mathrm{Cd}$ concentrations also exceeded the agricultural soil regulation guidance value $\left(0.6 \mu \mathrm{g} \mathrm{g}^{-1}\right)$ (GB156181995) by factors from 2.2 to 5.2 (Table 2).

The high $\mathrm{pH}$ (10.7) and high carbon level (45\%) of RSB were in agreement with other studies (Atkinson et al. 2010; Yuan et al. 2011; Luo et al. 2014) (Table 1). In addition, RSB used in the current study also contained plant essential nutrients, including $\mathrm{N}(1.59 \%)$ and water-soluble $\mathrm{P}$ and $\mathrm{K}$ at 0.66 and $47.6 \mathrm{mg} \mathrm{g}^{-1}$, respectively. These nutrient concentrations are in agreement with those reported for other rice straw 
biochar (Zheng et al. 2012). The Cd concentration in RSB was much lower than in the greenhouse soils (Table 1). The concentrations of $\mathrm{Cd}, \mathrm{Zn}, \mathrm{Pb}$, and As were all well below the threshold of sludge for agricultural use in China (GB189182002). The Cd concentrations in RSB were an order of magnitude lower than maximum values reported for a range of biochars, while $\mathrm{Zn}, \mathrm{Pb}$, and As concentrations were within a factor of 3 (Freddo et al. 2012). Concentrations of water soluble $\mathrm{Cd}, \mathrm{Zn}, \mathrm{Pb}$, and $\mathrm{As}$ in RSB were sufficiently low to be considered negligible.

\section{Influence of biochar on soil properties and lettuce yield}

In greenhouse $\mathrm{G} 18$, significant $(p<0.05)$ decreases in SBD (of $6 \%$ to $11 \%$ ) and increases in WHC (of $10 \%$ to $16 \%$ ) were observed with increasing RSB addition. Soil $\mathrm{pH}$ increased significantly $(p<0.05)$ by 0.2 to 0.8 units under RSB addition compared with the control (no RSB amendment). Concentrations of available $\mathrm{P}$ and $\mathrm{K}$ in soils increased by factors of up to 1.3 and $2.7(p<0.05)$, respectively, with the increase of RSB addition. However, the available N concentration did not change significantly under RSB amendment $(p<0.05)$ (Table 3). The improvement of soil properties, such as SBD and WHC, and increases in available nutrients following biochar addition, are usually conducive to crop production (Park et al. 2011; Uzoma et al. 2011; Alburquerque et al. 2014). In the present study, shoot weights (lettuce yield) increased significantly $(p<0.05)$ with increasing addition of RSB. Lettuce yield increased by factors of 1.08 and 1.15 under RSB addition at rates of 12 and $18 \mathrm{t} \mathrm{ha}^{-1}$, respectively. Among soil properties (available N, P, K concentrations, SBD and WHC), the decrease in SBD following RSB addition was a major contributor to the increase in lettuce yield $(p<0.001)$ (Table 4). The SBD is an important indicator of soil physical properties; its decrease is accompanied by loosening of soil and increasing soil porosity, which is conducive to root elongation and water retention, thus assisting improved uptake of essential nutrients for plant growth (Mukherjee et al. 2014; Ulyett et al. 2014). It is therefore reasonable to speculate that RSB addition increases root biomass and root length in lettuce
Table 4 Multiple linear regressions between $\mathrm{Cd}$ concentrations in lettuce shoot $\left(\left[\mathrm{Cd}_{\mathrm{v}}\right]\right)$ vs. DTPA-extractable $\mathrm{Cd}$ concentrations in soils $\left([\mathrm{Cd}]_{\mathrm{s}}\right)$ and shoot fresh weight of lettuce (SFW), between $[\mathrm{Cd}]_{\mathrm{s}}$ vs. soil $\mathrm{pH}$ and available $\mathrm{P}\left([\mathrm{P}]_{\mathrm{s}}\right)$, and between lettuce yield (Y) vs. soil available $\mathrm{N}, \mathrm{P}, \mathrm{K}$ concentrations, bulk density ([BD]) and water holding capacity in G18 $(n=16)$ using a stepwise method. Variables in regression equations were all significant $(p<0.05)$

\begin{tabular}{lll}
\hline Model & $r$ value & Significance \\
\hline$[\mathrm{Cd}]_{\mathrm{v}}=-0.160+0.817 \cdot[\mathrm{Cd}]_{\mathrm{s}}$ & 0.719 & $p<0.01$ \\
{$[\mathrm{Cd}]_{\mathrm{s}}=1.329-0.105 \cdot \mathrm{pH}-0.002 \cdot[\mathrm{P}]_{\mathrm{s}}$} & 0.892 & $p<0.001$ \\
$Y=46.703-17.787 \cdot[\mathrm{BD}]$ & 0.780 & $p<0.001$ \\
\hline
\end{tabular}

although this were not tested. In addition, there were also significant correlations between lettuce yield vs. available concentrations of K $(p=0.003)$ and WHC $(p=0.018)$, respectively (Fig. S1). The high level of available nutrients in all of the greenhouse soils may be attributed to the excessive application of fertilizers, as indicated by a previous report (Ju et al. 2007). Given the already elevated $P$ and $K$ status, the addition of biochar-associated $\mathrm{P}$ and $\mathrm{K}$ is unlikely to have contributed to the observed increase in lettuce yield.

In G5, G6, G20, G21, concentrations of available $\mathrm{K}$ in all soils increased significantly $(p<0.05)$ (by 59\%-197\%) after $\mathrm{RSB}$ addition. In the case of nil $\mathrm{K}$ applied in all greenhouses, lettuce yield increased by $8 \%-11 \%(p<0.05)$ regardless of whether RSB was added using the band or broadcast method (Table S1). Available concentrations of soil $\mathrm{N}$ and $\mathrm{P}$ were not significantly influenced $(p<0.05)$ by RSB addition. Soil $\mathrm{pH}$ in G20 and G21 were significantly elevated $(p<0.05)$ by 0.4 and 0.4 units after RSB addition, respectively; however, the soil $\mathrm{pH}$ did not change significantly in G5 and G6 $(p<0.05)$.

\section{DTPA-extractable concentrations of Cd}

Biochar addition significantly $(p<0.05)$ decreased DTPAextractable concentrations of soil $\mathrm{Cd}\left(0.46 \mu \mathrm{g} \mathrm{g}^{-1}\right)$ by $8 \%$ $25 \%$, especially at the addition rate of $18 \mathrm{t} \mathrm{ha}^{-1}$ in G18 $(p<0.001)$ (Fig. 1a). These decreases in Cd extractability may be attributed to the increases in $\mathrm{pH}$ and available $\mathrm{P}$ concentrations following RSB amendment. There were

Table 3 Influence of biochar additions on soil $\mathrm{pH}$, soil bulk density, water holding capacity (WHC), available nutrient concentrations, and lettuce yield in G18. Values are given as mean \pm standard deviation $(n=4)$

\begin{tabular}{|c|c|c|c|c|c|c|c|}
\hline \multirow{2}{*}{$\begin{array}{l}\text { Biochar addition } \\
\left(\mathrm{t} \mathrm{ha}^{-1}\right)\end{array}$} & \multirow[t]{2}{*}{ Soil pH } & \multirow{2}{*}{$\begin{array}{l}\text { Soil bulk density } \\
\left(\mathrm{g} \mathrm{cm}^{-3}\right)\end{array}$} & \multirow[t]{2}{*}{$\mathrm{WHC}(\%)$} & \multicolumn{3}{|c|}{ Available nutrient $\left(\mathrm{mg} \mathrm{g}^{-1}\right)$} & \multirow[t]{2}{*}{ Lettuce yield $\left(\mathrm{t} \mathrm{ha}^{-1}\right)$} \\
\hline & & & & $\mathrm{N}$ & $\mathrm{P}$ & $\mathrm{K}$ & \\
\hline 0 & $7.6 \pm 0.1 \mathrm{c}$ & $1.34 \pm 0.05 \mathrm{a}$ & $20.1 \pm 1.4 \mathrm{c}$ & $0.19 \pm 0.04 \mathrm{a}$ & $0.43 \pm 0.06 \mathrm{~b}$ & $0.47 \pm 0.1 \mathrm{c}$ & $22.9 \pm 0.9 \mathrm{c}$ \\
\hline 6 & $7.8 \pm 0.1 \mathrm{~b}$ & $1.26 \pm 0.04 \mathrm{~b}$ & $21.0 \pm 1.2 \mathrm{bc}$ & $0.18 \pm 0.02 \mathrm{a}$ & $0.46 \pm 0.06 \mathrm{ab}$ & $0.73 \pm 0.2 b$ & $23.8 \pm 0.7 \mathrm{bc}$ \\
\hline 12 & $8.0 \pm 0.2 \mathrm{~b}$ & $1.23 \pm 0.03 \mathrm{bc}$ & $22.2 \pm 1.5 \mathrm{ab}$ & $0.19 \pm 0.01 \mathrm{a}$ & $0.48 \pm 0.06 \mathrm{ab}$ & $0.86 \pm 0.1 \mathrm{~b}$ & $24.6 \pm 0.9 \mathrm{~b}$ \\
\hline 18 & $8.4 \pm 0.1 \mathrm{a}$ & $1.19 \pm 0.02 \mathrm{c}$ & $23.4 \pm 0.7 \mathrm{a}$ & $0.18 \pm 0.01 \mathrm{a}$ & $0.56 \pm 0.11 \mathrm{a}$ & $1.27 \pm 0.2 \mathrm{a}$ & $26.3 \pm 0.7 \mathrm{a}$ \\
\hline
\end{tabular}

Different letters in the same column represent significant difference between treatments $(p<0.05)(n=4)$ 
significant correlations between DTPA-extractable concentrations of $\mathrm{Cd}$ with soil $\mathrm{pH}(p<0.001)$ and with available $\mathrm{P}$ $(p=0.008)$ (respectively, Fig. 2a, b). Both variables (soil $\mathrm{pH}$ and available $\mathrm{P}$ concentration) contributed significantly $(p<0.05)$ to the immobilization of soil Cd (Table 4$)$.

Following RSB amendment in broadcast application in G5 (10 $\left.\mathrm{tha}^{-1}\right)$ and $\mathrm{G} 21$ (16 $\left.\mathrm{tha}^{-1}\right)$ and in band application in G6 $\left(5 \mathrm{t} \mathrm{ha}^{-1}\right)$ and $\mathrm{G} 20\left(8 \mathrm{t} \mathrm{ha}^{-1}\right)$, DTPA-extractable concentrations of Cd decreased significantly $(p<0.05)$ by $20 \%, 30 \%$, and $32 \%$ in G21, G6, and G20, respectively (although no significant reduction was observed in G5) (Fig. 3a). The decrease rates of DTPA-extractable concentrations of $\mathrm{Cd}$ caused by RSB amendment were increased with increasing extractable $\mathrm{Cd}$ in soils initially in the four greenhouses.

Concentrations of DTPA-extractable Fe, Mn, and $\mathrm{Zn}$ in soils were measured as these can influence the fate of $\mathrm{Cd}$ in soil by affecting its availability in soils (Table S2). Soil concentrations of DTPA-extractable Fe and Mn in G18 decreased with increasing RSB additions by up to $33 \%$ $(p<0.01)$ and $28 \%(p<0.05)$, respectively. The DTPAextractable $\mathrm{Zn}$ concentrations did not change significantly $(p<0.05)$ after RSB addition. In G5, G6, G20, and G21, concentrations of DTPA-extractable Fe decreased by $22 \%-$ $31 \%(p<0.05)$ after RSB addition; however, $\mathrm{Zn}$ concentrations were not significantly affected $(p<0.05)$. The DTPA-extractable Mn concentrations reduced by $24 \%$ in G20 only $(p<0.05)$.

Fig. 2 Relationship between DTPA-extractable concentration of $\mathrm{Cd}$, under biochar additions at different rates $\left(0,6,12,18 \mathrm{tha}^{-1}\right)$ in greenhouse $\mathrm{G} 18$ vs. soil $\mathrm{pH}$ (a) vs. soil-available $\mathrm{P}$ concentration (b). The relationship between shoot $\mathrm{Cd}$ concentrations vs. DTPA-extractable concentrations of Cd (c) vs. shoot biomass of lettuce (lettuce yield) $(\mathbf{d})$
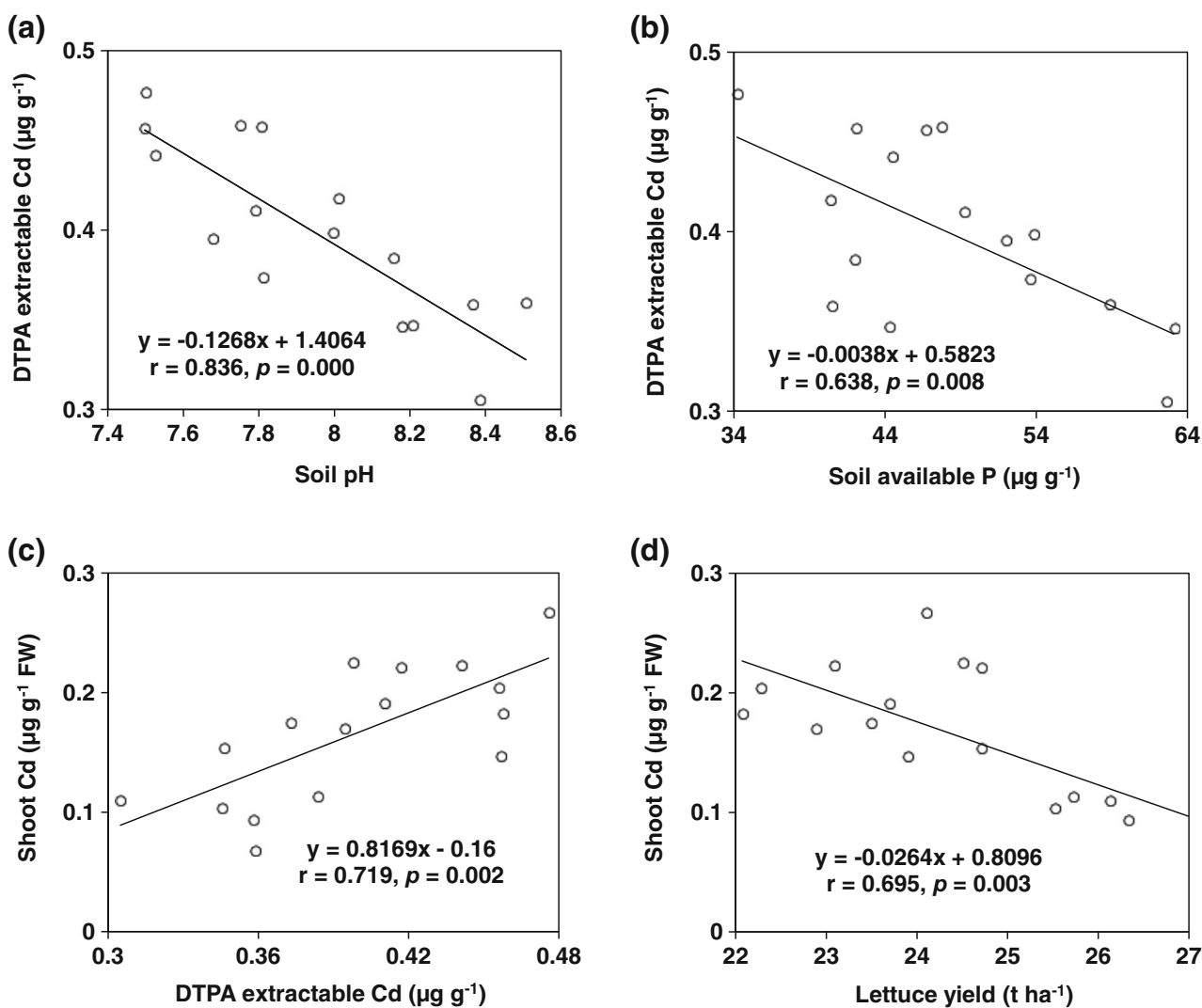

\section{Cd accumulation in lettuce}

Shoot $\mathrm{Cd}$ concentrations in lettuce were reduced by up to $57 \%$ $(p<0.001)\left(0.22 \mu \mathrm{g} \mathrm{g}^{-1}\right.$ fresh weight, $\mathrm{FW}$, initially) with increasing RSB additions in G18 (Fig. 1b). There was a significant ( $p=0.002)$ positive correlation between shoot Cd concentrations in lettuce and DTPA-extractable concentrations of $\mathrm{Cd}$ in soils (Fig. 2c). In addition, lettuce yield, namely, shoot biomass (SFW), was also linearly correlated with shoot Cd concentrations ( $p=0.003$ ) (Fig. 2d). The SFW was excluded in multiple linear regression analysis between $\mathrm{Cd}$ concentrations in lettuce shoot $\left([\mathrm{Cd}]_{\mathrm{v}}\right)$ vs. DTPA-extractable Cd concentrations in soils $\left([\mathrm{Cd}]_{\mathrm{s}}\right)$ and SFW using a stepwise method. This analysis indicated that it was the immobilization of $\mathrm{Cd}$ in soils rather than the biomass dilution that underpinned the reduction in $\mathrm{Cd}$ concentrations in lettuce shoots following RSB addition (Table 4).

In G6 and G20, where RSB was applied in bands, Cd concentrations in lettuce shoots decreased by $29 \%$ and $42 \%$, respectively. Where RSB was applied by broadcasting (in G21 and G5), a significant $(p<0.05)$ decrease in shoot Cd concentration of lettuce was only observed in the higher $\mathrm{Cd}$ concentration soils (Fig. 3b). Compared with the national standard, shoot $\mathrm{Cd}$ concentrations under un-amended treatments in G6, G18, G20 were $0.1 \%, 10 \%$, and $23 \%$ higher, respectively, than the Chinese regulation limit set for food $\left(0.2 \mu \mathrm{g} \mathrm{g}^{-1}\right.$ FW) (MHPRC and SAC 2012). Shoot Cd concentrations of lettuce in these three greenhouses were reduced to below the 
(a)

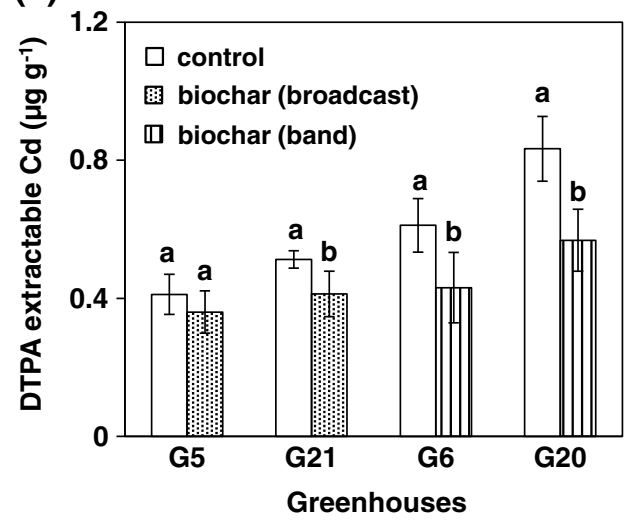

Fig. 3 DTPA-extractable Cd concentrations in four greenhouses (G5, G6, G20, G21) in soils (a) and shoot Cd concentrations of leaf lettuce (L. sativa L. var ramosa Hort.) (b), in the un-amended control treatment ( $\square$ ), broadcast biochar application (眀) and band biochar application

regulation limit following RSB amendment. Shoot Cd concentrations in lettuce did not exceed the maximum allowable limit in G5 and G21, although soil Cd concentrations were higher than the guidance value for agricultural soil in China.

Root $\mathrm{Cd}$ concentrations in lettuce, based on dry weight, are shown in Table S2. Root Cd concentrations decreased by up to $53 \%(p<0.01)$ with increasing RSB additions in G18. Decreases in root Cd concentrations of $34 \%$ and $42 \%$ $(p<0.05)$ were caused by band RSB additions in G6 and G20, respectively. Broadcast application of RSB significantly reduced root $\mathrm{Cd}$ concentrations by $33 \%(p<0.05)$ in $\mathrm{G} 21$, but not in G5.

\section{Estimated daily intake of Cd and HQs}

The EDIs and HQs of Cd are listed in Table 5. The EDIs of Cd in un-amended treatments in the five experimental (b)

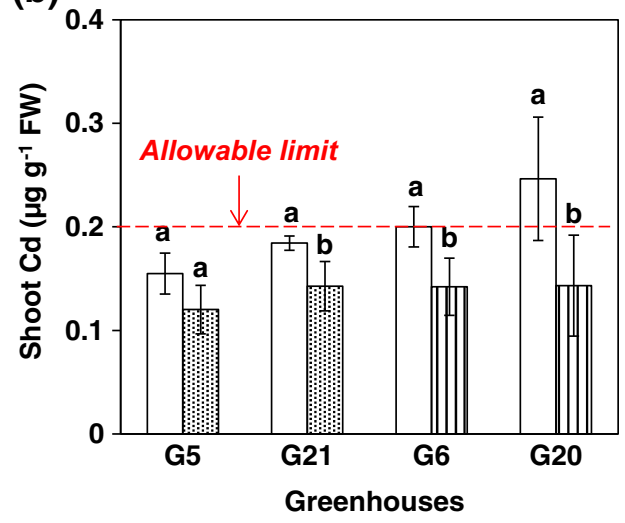

(Ш). Different letters above the bars indicate significant differences at $p<0.05$ comparing biochar application treatment with the un-amended control treatment $(n=4)$

greenhouses ranged from 0.70 to $1.11 \mu \mathrm{g} \mathrm{kg}^{-1}$ day $^{-1}$. After RSB addition, EDIs for Cd decreased by up to $57 \%, 22 \%$, $23 \%, 29 \%$, and $42 \%$ in G18, G5, G21, G6, and G20, respectively. Among these five greenhouses, Cd EDI was above the oral reference dose $\left(1.0 \mathrm{\mu g} \mathrm{kg}^{-1} \mathrm{day}^{-1}\right)$ set by the USEPA only in the un-amended treatment of $\mathrm{G} 20$ and as a consequence its HQ was $>1$ (Table 5). However, the Cd HQ in G20 decreased from 1.11 in the control to 0.65 under RSB amendment.

\section{Discussion}

To our knowledge, this is the first report to investigate the influence of biochar on the accumulation of $\mathrm{Cd}$ in lettuce under greenhouse vegetable production, and the first study to apply biochar under band application. The soils of all experimental greenhouses were tainted by $\mathrm{Cd}$ due to historically
Table 5 EDI and HQ for Cd associated with the consumption of vegetable grown in control soils and soils amended with biochar. Where HQ was $>1$ this has been indicated in italics

\begin{tabular}{llcll}
\hline Greenhouses & Application ways & Biochar dose $\left(\mathrm{t} \mathrm{ha}^{-1}\right)$ & EDI $\left(\mu \mathrm{g} \mathrm{kg}^{-1} \mathrm{day}^{-1}\right)$ & $\mathrm{HQ}$ \\
\hline G18 & Control & 0 & 0.99 & 0.99 \\
& Broadcast & 6 & 0.82 & 0.82 \\
& Broadcast & 12 & 0.66 & 0.66 \\
& Broadcast & 18 & 0.42 & 0.42 \\
G5 & Control & 0 & 0.70 & 0.70 \\
& Broadcast & 10 & 0.54 & 0.54 \\
G21 & Control & 0 & 0.83 & 0.83 \\
& Broadcast & 16 & 0.64 & 0.64 \\
G6 & Control & 0 & 0.90 & 0.90 \\
& Band & 5 & 0.64 & 0.64 \\
G20 & Control & 0 & 1.11 & 1.11 \\
& Band & 8 & 0.65 & 0.65 \\
\hline
\end{tabular}

Control, broadcast, and band represent un-amended with biochar, biochar application in broadcast placement, and biochar application in band placement, respectively 
frequent and large applications of manure containing high $\mathrm{Cd}$ levels. Both band and broadcast applications of RSB successfully reduced shoot $\mathrm{Cd}$ concentrations in lettuce (Fig. 3b). The band application, of course, halved the mass of biochar required for soil amelioration and therefore represents an opportunity to reduce remediation costs.

Soil $\mathrm{pH}$ and $\mathrm{P}$ were the key factors decreasing DTPAextractable concentrations of soil $\mathrm{Cd}$ after RSB addition. The biochar-induced $\mathrm{pH}$ increase (0.2-0.8 units) was strongly correlated with the immobilization of $\mathrm{Cd}$ (Tables 3 and 4; Fig. 2a). Because the number of negatively charged surface sites in soil increases with increasing $\mathrm{pH}$, the sorption capacity of soil to cationic metals correspondingly increases (Bradl 2004). The $\mathrm{pH}$ increase after the application of biochar could reduce metal extractability by promoting metal (co)precipitation and metal adsorption on specific biochar mineral phases (Rees et al. 2014; Yang et al. 2016). Moreover, other studies have shown that metal mobility reduced in the presence of biochar because of the metal adsorption on the biochar surface (especially on carboxylic and phenolic groups) (Uchimiya et al. 2011a, b). In addition to an increase in soil $\mathrm{pH}, \mathrm{P}$ entering the soil with RSB application may also have been a contributing factor in immobilizing $\mathrm{Cd}$ through the formation of phosphate precipitates (McGowen et al. 2001; Zheng et al. 2011) (Table 1). Availability of soil $\mathrm{P}$, after RSB addition, was observed to increase, and a significant correlation between concentrations of soil available $\mathrm{P}$ and DTPA-extractable concentrations of soil $\mathrm{Cd}$ was shown (Table 3, Fig. 2b).

Soils of the five experimental greenhouses exhibited a wide range of $\mathrm{Cd}$ concentrations decreasing in the following order: $\mathrm{G} 5<\mathrm{G} 6<\mathrm{G} 18<\mathrm{G} 20<\mathrm{G} 21$. This was noticeably different to the order observed for extractable Cd: $\mathrm{G} 5<\mathrm{G} 18<\mathrm{G} 21<\mathrm{G} 6<\mathrm{G} 20$ (Table 2, Fig. 3a). This may be attributed to the difference of soil properties between the greenhouses, which was gradually caused by different fertilizer, water, and vegetable planting management over the years. For instance, soil pH (7.3-7.8), available K (0.25$\left.0.54 \mathrm{mg} \mathrm{g}^{-1}\right)$, and available $\mathrm{P}\left(0.31-0.48 \mathrm{mg} \mathrm{g}^{-1}\right)$ were notably different among the five experimental greenhouses. In addition to these factors, Fe and $\mathrm{Mn}$ oxides, competitive ions (e.g., $\mathrm{Zn}$ ), salinity, and chloride levels in the greenhouse soils could also influence the availability of soil $\mathrm{Cd}$ (Adams et al. 2004). Contrasting Cd concentration/availability and soil properties may have been caused by the variability in application of animal manure containing high levels of organic matter. These applications were large and frequent ( $>40 \mathrm{t} \mathrm{ha}^{-1}$ year $^{-1}$ ) in all greenhouses. The $\mathrm{Cd}$ concentration can be strongly immobilized through specific adsorption reactions with organic matter (Cui et al. 2016; van Herwijnen et al. 2007; Karlsson et al. 2007), although it can also occur when binding with dissolved organic matter (Del Castilho et al. 1993; Kalbitz and Wennrich 1998).
The magnitude of decrease in DTPA-extractable concentrations of $\mathrm{Cd}$ was in the order G5 $<\mathrm{G} 21<\mathrm{G} 6<\mathrm{G} 20$. This order was the same as that of initial extractable $\mathrm{Cd}$ in soil (Fig. 3a). The effect of RSB amendment on reducing DTPAextractable concentrations of $\mathrm{Cd}$ increased with increasing initial extractable $\mathrm{Cd}$ in soil. One possible interpretation is that a lesser amount of extractable Cd was present in the soil and thus a smaller amount of $\mathrm{Cd}$ was able to diffuse to the biochar surface or become dissolved in soil solution to be adsorbed or precipitated. This supports the suggestion that diffusion of $\mathrm{Cd}$ ions to the root surface is the dominant pathway in soil (Lorenz et al. 1994). In addition, the decreases in DTPAextractable concentrations of $\mathrm{Fe}$ in soils of all greenhouses and that of $\mathrm{Mn}$ in $\mathrm{G} 20(p<0.05)$ (Table S2) may further immobilize soil $\mathrm{Cd}$ through co-precipitation with $\mathrm{Fe} / \mathrm{Mn}$ oxides, which are abundant in soils and have great capacity to sorb Cd (Suda and Makino 2016).

Shoot $\mathrm{Cd}$ concentrations in lettuce decreased significantly after RSB addition, except in G5 (Figs. 1b and 3b). The decreases in shoot $\mathrm{Cd}$ concentration were attributed primarily to the decreases in extractable $\mathrm{Cd}$ in soil though there was a significant $(p=0.003)$ negative correlation between shoot biomass (lettuce yield) and shoot $\mathrm{Cd}$ concentration (Fig. 2c, $\mathrm{d}$, Table 4). The Cd concentrations in lettuce shoot of G6, G18, and G20 among the five experimental greenhouses exceeded the Chinese regulation limit set for food $\left(0.2 \mu \mathrm{g} \mathrm{g}^{-1} \mathrm{FW}\right)$ by $0.1 \%-23.2 \%$. However, RSB addition successfully decreased the Cd level in lettuce shoots to an acceptable level $\left(<0.2 \mu \mathrm{g} \mathrm{g}^{-1} \mathrm{FW}\right)$ when applied using both band and broadcast methods. In addition, concentrations of other nutrient elements such as $\mathrm{K}, \mathrm{P}, \mathrm{Ca}, \mathrm{Mg}, \mathrm{Zn}$, and Fe were also determined in lettuce shoots (Table S3). Shoot concentrations of $\mathrm{P}, \mathrm{Ca}, \mathrm{Mg}, \mathrm{Zn}$ and $\mathrm{Fe}$ were not significantly influenced by RSB addition $(p<0.05)$. However, RSB addition caused a significant increase in $\mathrm{K}$ concentration of up to $27 \%$ in $\mathrm{G} 18$ and $18-26 \%$ in G5, G6, G20 and G21 ( $p<0.05)$. Thus, there was an improvement in the quality of lettuce in response to elevated K level after RSB addition. The observation of no clear effect on Fe concentrations in lettuce shoot, despite the reduction in Fe extractability (Table S2), following RSB additions may be attributed to the mechanisms of plants for acquiring $\mathrm{Fe}$ and the initially high Fe availability (27.7$39.2 \mu \mathrm{g} \mathrm{g}^{-1}$ ) (Marschner and Rohmeld 1994; Zheng et al. 2015b).

Shoot $\mathrm{Cd}$ concentration exceeded the maximum allowable limit for lettuce grown in control soils (G18 and G20), whereas $\mathrm{Cd}$ concentrations in lettuce shoots grown in G6 soil was close to the limit. Moreover, $\mathrm{Cd}$ concentrations in lettuce shoots grown in the other control soils were below the regulatory limit, although the soils in these greenhouses had higher $\mathrm{Cd}$ concentrations that were above the regulatory limit for soils (Table 2). This was expected because the bioaccumulation factor (BF) of $\mathrm{Cd}$, determined as a ratio of $\mathrm{Cd}$ 
concentration in lettuce shoot (edible parts) to that in soil, is an intricate function of the genotype of the plant and the soil properties such as $\mathrm{pH}$, organic carbon content, cation exchange capacity, and clay content (Gaw et al. 2008; Zhang et al. 2014; Mombo et al. 2016). The BFs changed in accordance with shoot $\mathrm{Cd}$ concentrations and ranged from 0.04 to 0.11 (Table S2). These are similar to results reported in other studies (Yang et al. 2009; Zhang et al. 2014; Mombo et al. 2016).

The observation of HQs with values less than 1 indicate daily intake of $\mathrm{Cd}$ to be less than the reference dose, implying an absence of unacceptable risk to human health. The EDI and $\mathrm{HQ}$ values of $\mathrm{Cd}$ among the experimental greenhouses were decreased by up to $57.2 \%$ and $57.2 \%$, respectively, after RSB additions (Table 5). The most notable result was that RSB addition decreased Cd HQ for G20 from an initial 1.11 to an acceptable level $(<1)$. The results obtained in the present study are significant as they showed potential for biochar amendment to improve vegetable safety through the sequestration of bioavailable $\mathrm{Cd}$ from greenhouse soil to edible parts of the vegetable. Consequently, the EDIs and HQ associated with vegetable consumption were reduced.

Other studies investigating effects of biochar on lettuce growth and/or Cd accumulation in pot experiments support our results (Gunes et al. 2014; Upadhyay et al. 2014; Kim et al. 2015; Ye et al. 2016). Biochar derived from paper mill sludge significantly $(p<0.05)$ decreased Cd concentration in lettuce leaves by $26 \%-71 \%$ and increased lettuce biomass (Kim et al. 2015). Additions of poultry manure biochar (PMB) resulted in significant $(p<0.05)$ increases in shoot $\mathrm{K}$ concentration of lettuce (Gunes et al. 2014), which supports our results. However, the reported increases in shoot concentrations of $\mathrm{P}$ and reductions in $\mathrm{Fe}$ and $\mathrm{Zn}$ concentrations after PMB addition disagreed with the present study. This may be attributed to the initially high available P level (0.31$0.48 \mathrm{mg} \mathrm{g}^{-1}$ ) in greenhouse soils in the present study and the much higher concentrations of available $\mathrm{Fe}$ and $\mathrm{Zn}$ in greenhouse soils than that in Gunes et al. (2014) (27.7-39.2 vs. $6.4 \mu \mathrm{g} \mathrm{g}^{-1}$ for Fe and 9.9-12.9 vs. $0.72 \mu \mathrm{g} \mathrm{g}^{-1}$ for $\mathrm{Zn}$ ). Further studies have indicated that biochars, such as gasification and fast-pyrolysis pine and poplar wood chars, inhibited lettuce growth (Marks et al. 2014), and coffee husk char induced an increase of extractable $\mathrm{Cd}$ in a sandy loam soil despite a decrease in Cd concentration in lettuce (Woldetsadik et al. 2016). Such variability in outcome might relate to the distinct properties (such as nutrient composition, surface area, and volatile matter content) of biochars made from diverse materials or under different pyrolysis conditions, which cause varying effects on Cd immobilization and lettuce growth performance (Marks et al. 2014; Woldetsadik et al. 2016).

Regarding the economic cost and benefits of biochar, it was cost effective to add biochar, by virtue of saving potassic fertilizer and increasing vegetable yield. The band application of biochar provides an opportunity to halve biochar cost. Thus, we suggest biochar application in bands as a recommended remediation approach for vegetable greenhouses contaminated by $\mathrm{Cd}$.

\section{Conclusions}

Rice straw biochar addition effectively reduced Cd concentrations in lettuce shoots under greenhouse vegetable production primarily through immobilization of soil $\mathrm{Cd}$ rather than biomass dilution. Shoot $\mathrm{Cd}$ concentrations in lettuce were decreased by up to $57.2 \%$ with increased RSB addition. Whether RSB was amended using broadcast or band application, $\mathrm{Cd}$ concentrations in lettuce shoots were reduced. Despite soil $\mathrm{Cd}$ concentrations being above guideline values for agricultural land, the levels of $\mathrm{Cd}$ in lettuce were reduced to a level below the Chinese regulation limit set for food $\left(0.2 \mu \mathrm{g} \mathrm{g}^{-1} \mathrm{FW}\right)$ in all RSB-treated soils. Lettuce yields were increased significantly by $8.2 \%-14.8 \%$ along with decreases in SBD, increases in WHC, and available nutrient ( $\mathrm{K}$ and $\mathrm{P}$ ) concentration following RSB addition.

Biochar application in bands is a recommended method to constrain biochar costs, to immobilize soil $\mathrm{Cd}$, and to reduce $\mathrm{Cd}$ accumulation in edible parts of vegetables. Given that rice straw is a readily available agricultural residue, we suggest that its conversion to biochar and incorporation into greenhouse soil contaminated by $\mathrm{Cd}$, especially in band application, could be an achievable and cost-effective approach to mitigate $\mathrm{Cd}$ exposure associated with vegetable consumption.

Acknowledgements This work was financially supported by National Natural Science Foundation of China (No. 41501336) and the National High Technology Research and Development Program of China (863 Program, 2013AA06A209). Reid acknowledges support from the Chinese Academy of Science Presidents International Fellowship Award scheme-Grant No. 2016VEA040.

\section{References}

Adams ML, Zhao FJ, McGrath SP, Nicholson FA, Chambers BJ (2004) Predicting cadmium concentrations in wheat and barley grain using soil properties. J Environ Qual 33:532-541

Alburquerque JA, Calero JM, Barrón V, Torrent J, Campillo MC, Gallardo A, Villar R (2014) Effects of biochars produced from different feedstocks on soil properties and sunflower growth. J Plant Nutr Soil Sc 177:16-25

Atkinson CJ, Fitzgerald JD, Hipps NA (2010) Potential mechanisms for achieving agricultural benefits from biochar application to temperate soils: a review. Plant Soil 337:1-18

Bradl HB (2004) Adsorption of heavy metal ions on soils and soils constituents. J Colloid Interface Sci 277:1-18

BSY (Beijing Statistical Yearbook) (2015) Chapter 8: People's life (in Chinese) http://www.bjstats.gov.cn/nj/main/2015-tjnj/indexch.htm. Accessed 26 April 2016 
CNEMC (China National Environmental Monitoring Center) (1990) Background values of soil elements in China, 1st edn. Chinese Environmental Science Press, Beijing (in Chinese)

CSY (China Statistical Yearbook) (2015) National Bureau of Statistics of China compiles. Chapter 6: People's living conditions (in Chinese) http://www.stats.gov.cn/tjsj/ndsj/2015/indexch.htm. Accessed 26 Apr 2016

Cui LQ, Pan GX, Li LQ, Bian RJ, Liu XY, Yan JL, Quan GX, Ding C, Chen TM, Liu Y, Liu YM, Yin CT, Wei CP, Yang YG, Hussain Q (2016) Continuous immobilization of cadmium and lead in biochar amended contaminated paddy soil: a five-year field experiment. Ecol Eng 93:1-8

Del Castilho P, Chardon WJ, Salomons W (1993) Influence of cattlemanure slurry application on the solubility of cadmium, copper and zinc in a manured acidic, loamy-sand soil. J Environ Qual 2: 689-697

EFSA (European Food Safety Authority) (2009) Scientific opinion on cadmium in food. EFSA J 980:1-39

Ettler V, Mihaljevič M, Šebek O, Nechutný Z (2007) Antimony availability in highly polluted soils and sediments-a comparison of single extractions. Chemosphere 68:455-463

Freddo A, Cai C, Reid BJ (2012) Environmental contextualisation of potential toxic elements and polycyclic aromatic hydrocarbons in biochar. Environ Pollut 171:18-24

Gaw SK, Kim ND, Northcott GL, Wilkins AL, Robinson G (2008) Uptake of Sigma DDT, arsenic, cadmium, copper, and lead by lettuce and radish grown in contaminated horticultural soils. J Agr Food Chem 56:6584-6593

Gunes A, Inal A, Taskin MB, Sahin O, Kaya EC, Atakol A (2014) Effect of phosphorus-enriched biochar and poultry manure on growth and mineral composition of lettuce (Lactuca sativa L. cv.) grown in alkaline soil. Soil Use Manage 30(2):182-188

Ju XT, Kou CL, Christie P, Dou ZX, Zhang FS (2007) Changes in the soil environment from excessive application of fertilizers and manures to two contrasting intensive cropping systems on the North China Plain. Environ Pollut 145:497-506

Kalbitz K, Wennrich R (1998) Mobilization of heavy metals and arsenic in polluted wetland soils and its dependence on dissolved organic matter. Sci Total Environ 209(1):27-39

Karlsson T, Elgh-Dalgren K, Bjorn E, Skyllberg U (2007) Complexation of cadmium to sulfur and oxygen functional groups in an organic soil. Geochim Cosmochim Ac 71(3):604-614

Khan S, Lin A, Zhang S, Hu Q, Zhu YG (2008) Accumulation of polycyclic aromatic hydrocarbons and heavy metals in lettuce grown in the soils contaminated with long-term wastewater irrigation. J Hazard Mater 152(2):506-515

Khan S, Chao C, Waqas M, Arp HPH, Zhu YG (2013) Sewage sludge biochar influence upon rice (Oryza sativa L) yield, metal bioaccumulation and greenhouse gas emissions from acidic paddy soil. Environ Sci Technol 47:8624-8632

Khan S, Reid BJ, Li G, Zhu YG (2014) Application of biochar to soil reduces cancer risk via rice consumption: a case study in Miaoqian village, Longyan, China. Environ Int 68:154-161

Kim HS, Kim KR, Ok YS, Lee YK, Kluge B, Wessolek G, Kim WI, Kim $\mathrm{KH}$ (2015) Examination of three different organic waste biochars as soil amendment for metal-contaminated agricultural soils. Water Air Soil Pollut 226:282

Li Y, Wang YB, Gou X, Su YB, Wang G (2006) Risk assessment of heavy metals in soils and vegetables around non-ferrous metals mining and smelting sites, Baiyin, China. J Environ Sci (China) 18:1124-1134

Liu YX, HH L, Yang SM, Wang YF (2016) Impacts of biochar addition on rice yield and soil properties in a cold waterlogged paddy for two crop seasons. Field Crop Res 191:161-167

Lorenz SE, Hamon RE, McGrath SP (1994) Differences between soil solutions obtained from rhizosphere and non-rhizosphere soils by water displacement and soil centrifugation. Eur J Soil Sci 45:431438

Lu R (2000) Soil agricultural chemical analysis method. China Agriculture Science and Technique Press, Beijing

Luo L, Ma Y, Zhang S, Wei D, Zhu YG (2009) An inventory of trace element inputs to agricultural soils in China. J Environ Manag 90: 2524-2530

Luo F, Song J, Xia W, Dong M, Chen M, Soudek P (2014) Characterization of contaminants and evaluation of the suitability for land application of maize and sludge biochars. Environ Sci Pollut R 21:8707-8717

Marks EAN, Alcaniz JM, Domene X (2014) Unintended effects of biochars on short-term plant growth in a calcareous soil. Plant Soil 385(1-2):87-105

Marschner H, Rohmeld V (1994) Strategies of plants for acquisition of iron. Plant Soil 165:375-388

McGowen SL, Basta NT, Brown GO (2001) Use of diammonium phosphate to reduce heavy metal solubility and transport in smelter-contaminated soil. J Environ Qual 30:493-500

MHPRC and SAC (2012) Maximum levels of contaminants in foods (GB2762-2012)

Mombo S, Foucault Y, Deola F, Gaillard I, Goix S, Shahid M, Schreck E, Pierart A, Dumat C (2016) Management of human health risk in the context of kitchen gardens polluted by lead and cadmium near a lead recycling company. J Soils Sediments 16:1214-1224

Mukherjee A, Lal R, Zimmerman AR (2014) Effects of biochar and other amendments on the physical properties and greenhouse gas emissions of an artificially degraded soil. Sci Total Environ 487:26-36

NCDSR (Nutrition and Chronic Disease Status of Chinese Residents Report) (2015) National Health and Family Planning Commission of the People's Republic of China compiles (in Chinese)

Olmo M, Lozano AM, Barron V, Villar R (2016) Spatial heterogeneity of soil biochar content affects soil quality and wheat growth and yield. Sci Total Environ 562:690-700

Park JH, Choppala GK, Bolan NS, Chung JW, Chuasavathi T (2011) Biochar reduces the bioavailability and phytotoxicity of heavy metals. Plant Soil 348:439-451

Rees F, Simonnot MO, Morel JL (2014) Short-term effects of biochar on soil heavy metal mobility are controlled by intra-particle diffusion and soil $\mathrm{pH}$ increase. Eur J Soil Sci 65:149-161

Sorrenti G, Toselli M (2016) Soil leaching as affected by the amendment with biochar and compost. Agric Ecosyst Environ 226:56-64

Suda A, Makino T (2016) Functional effects of manganese and iron oxides on the dynamics of trace elements in soils with a special focus on arsenic and cadmium: a review. Geoderma 270:68-75

Sui YH, Gao JP, Liu CH, Zhang WZ, Lan Y, Li SH, Meng J, ZJ X, Tang L (2016) Interactive effects of straw-derived biochar and $\mathrm{N}$ fertilization on soil $\mathrm{C}$ storage and rice productivity in rice paddies of Northeast China. Sci Total Environ 544:203-210

Uchimiya M, Chang S, Klasson KT (2011a) Screening biochars for heavy metal retention in soil: role of oxygen functional groups. J Hazard Mater 190:432-441

Uchimiya M, Wartelle LH, Klasson KT, Fortier CA, Lima IM (2011b) Influence of pyrolysis temperature on biochar property and function as a heavy metal sorbent in soil. J Agric Food Chem 59:2501-2510

Ulyett J, Sakrabani R, Kibblewhite M, Hann M (2014) Impact of biochar addition on water retention, nitrification and carbon dioxide evolution from two sandy loam soils. Eur J Soil Sci 65:96-104

Upadhyay KP, George D, Swift RS, Galea V (2014) The influence of biochar on growth of lettuce and potato. J Integr Agr 13(3):541-546

USEPA (2014) Integrated Risk Information System-database, Philadelphia PA, Washington, DC. http://www.epa.gov/iris/

Uzoma KC, Inoue M, Andry H, Fujimaki H, Zahoor A, Nishihara E (2011) Effect of cow manure biochar on maize productivity under sandy soil condition. Soil Use Manag 27:205-212 
van Herwijnen R, Hutchings TR, Al-Tabbaa A, Moffat AJ, Johns ML, Ouki SK (2007) Remediation of metal contaminated soil with mineral amended composts. Environ Pollut 150(3):347-354

Wang XL, Sato T, Xing BS, Tao S (2005) Health risks of heavy metals to the general public in Tianjin, China via consumption of vegetables and fish. Sci Total Environ 350:28-37

Woldetsadik D, Drechsel P, Keraita B, Marschner B, Itanna F, Gebrekidan H (2016) Effects of biochar and alkaline amendments on cadmium immobilization, selected nutrient and cadmium concentrations of lettuce (Lactuca sativa) in two contrasting soils. SpringerPlus 5:397

Yang Y, Zhang FS, Li HF, Jiang RF (2009) Accumulation of cadmium in the edible parts of six vegetable species grown in Cd-contaminated soils. J Environ Manag 90:1117-1122

Yang L, Huang B, Hu W, Chen Y, Mao M (2013) Assessment and source identification of trace metals in the soils of greenhouse vegetable production in eastern China. Ecotox Environ Safe 97:204-209

Yang X, Liu JJ, McGrouther K, Huang HG, Lu KP, Guo X, He LZ, Lin XM, Che L, Ye ZQ, Wang HL (2016) Effect of biochar on the extractability of heavy metals $(\mathrm{Cd}, \mathrm{Cu}, \mathrm{Pb}$, and $\mathrm{Zn})$ and enzyme activity in soil. Environ Sci Pollut R 23(2):974-984

Ye M, Sun MM, Feng YF, Wan JZ, Xie SN, Tian D, Zhao Y, Wu J, Hu F, Li HX, Jiang X (2016) Effect of biochar amendment on the control of soil sulfonamides, antibiotic-resistant bacteria, and gene enrichment in lettuce tissues. J Hazard Mater 309:219-227

Yuan JH, RK X, Zhang H (2011) The forms of alkalis in the biochar produced from crop residues at different temperatures. Bioresour Technol 102:3488-3497
Zeng X, Li L, Mei X (2008) Heavy metal content in Chinese vegetable plantation land soils and related source analysis. Agr. Sci China 7(9): $1115-1126$

Zhang C, Song N, Zeng GM, Jiang M, Zhang JC, XJ H, Chen AW, Zhen JM (2014) Bioaccumulation of zinc, lead, copper, and cadmium from contaminated sediments by native plant species and Acrida cinerea in South China. Environ Monit Assess 186:1735-1745

Zheng RL, Li HF, Jiang RF, Römheld V, Zhang FS, Zhao FJ (2011) The role of root hairs in cadmium acquisition by barley. Environ Pollut 159:408-415

Zheng RL, Cai C, Liang JH, Huang Q, Chen Z, Huang YZ, Arp HPH, Sun GX (2012) The effects of biochars from rice residue on the formation of iron plaque and the accumulation of $\mathrm{Cd}, \mathrm{Zn}, \mathrm{Pb}, \mathrm{As}$ in rice (Oryza sativa L.) seedlings. Chemosphere 89:856-862

Zheng RL, Chen Z, Cai C, Wang X, Huang Y, Xiao B, Sun GX (2013) Effect of biochars from rice husk, bran, and straw on heavy metal uptake by pot-grown wheat seedling in a historically contaminated soil. Bioresources 8(4):5965-5982

Zheng RL, Chen Z, Cai C, Tie B, Liu X, Reid BJ, Huang Q, Lei M, Sun GX, Baltrenaite E (2015a) Mitigating heavy metal accumulation into rice (Oryza sativa L.) using biochar amendment - a field experiment in Hunan, China. Environ Sci Pollut Res 22(14):11097-11108

Zheng RL, Wang NN, Sun GX, Xie ZB, Pang Z, Wang QH, JY W (2015b) Effects of biochar on soil properties and alfalfa growth and nutrient uptake in desertified land in Beijing suburb. J AgrEnviron Sci 34:904-912 (in Chinese) 